\title{
RESIDENT'S PERCEPTION OF THE ENVIRONMENTAL IMPACT OF TOURISM: A CASE STUDY OF THE BAWA COMMUNITY IN BUTTERWORTH, SOUTH AFRICA
}

\author{
Kimrochey Goliath-LUDIC ${ }^{*}$ \\ Walter Sisulu Universty, Department of Tourism, Hospitality and Sport Management, \\ 88 Buffalo Street, East London, 5200, South Africa, email: Kgoliath@wsu.ac.za

\section{Siyasanga YEKELA} \\ Walter Sisulu Universty, Department of Tourism, Hospitality and Sport Management, \\ 88 Buffalo Street, East London, 5200, South Africa, email: siyayekela@gmail.com
}

\begin{abstract}
Citation: Goliath-Ludic, K. \& Yekela, S. (2020). RESIDENT'S PERCEPTION OF THE ENVIRONMENTAL IMPACT OF TOURISM: A CASE STUDY OF THE BAWA COMMUNITY IN BUTTERWORTH, SOUTH AFRICA. GeoJournal of Tourism and Geosites, 33(4spl), $1527-1531$. https://doi.org/10.30892/gtg.334spl12-603
\end{abstract}

\begin{abstract}
Tourism is the fastest growing industry in the world. Understanding residents' perceptions of the industry assists tourism planners deliberately utilise resources to improve resident awareness and, therefore, increase the sustainability of future tourism development. The aim of the research paper was to determine resident's perception on the environmental impacts of tourism in Bawa community in Butterworth, South Africa. Quantitative and qualitative research approaches were both employed. A questionnaire was administered to collect data from the local commuity of Bawa.The main findings of the research reveals that the respondents perceive littering and overcrowding as the foremost issue to environmental impacts. This study contributes to the largely under researched area of tourism environmental impacts in Butterworth.
\end{abstract}

Key words: tourism, environment, environmental impacts, perception, residents, Bawa community, Butterworth, South Africa.

$* \quad * \quad * \quad * \quad * \quad *$

\section{INTRODUCTION}

Internationally, the tourism industry has emerged as a key force in boosting a nation's economy (Manzoor et al., 2019). The great growth of tourism activities over the years is associated with outstanding economic and social benefits. However, the amount and prospect of tourism growth raises concerns about its negative environmental impacts (Cucculelli and Goffi, 2015). Conserving the environment is of great importance as the same environments that attract and draw tourists to the destinations and promote tourism investment, can potentially be ruined by tourism. According to Stainton (2020) damage to environmental quality may eventually destroy the tourism industry. Robinot and Giannelloni (2010) state that with concerns about environmental degradation, many governments and green action groups within the tourism sector have gradually become aware of the need for more effective measures to safeguard the environment. For this reason, the green trend is becoming more accepted in the tourism sector and the growth of tourism activities is what makes the need to regulate the green message more pressing. This is often achieved by recognising those tourism businesses that actively encourage activities that do not harm the environment (Nash, 2020). The environment has been vital in tourism research since the $80 \mathrm{~s}$ and it continues to be an interesting topic in a time when global policies are aimed at conservation problems such as pollution, depletion of natural resources and deforestation.

In particular, the prospect of tourism activities as a means of environmental preservation and conservation have been widely investigated (Tony, 2019). According to a study by Dahal and Sapkota (2020) it was revealed that proper awareness towards waste management reduces the threat to environmental purity. Further, the role of proper waste management, energy use, and water use becomes a great asset to develop a sound tourism industry. Tourism has the potential to increase public appreciation of the environment and to spread awareness of environmental problems when it brings people into closer contact with nature and the environment (Stainton, 2020).

The quality of the environment, both natural and man-made, is essential to tourism. According to Arintoko et al. (2020) some research results show that environmental impact is considered a factor to measure sustainable tourism (Lee et al., 2013; Lundberg, 2015; Vargas-Sánchez et al., 2009; Diedrich and García-Buades, 2009). Mangwane et al. (2019) suggest that to maintain sustainable tourism, local communities must engage in responsible tourism initiatives and must practise responsible tourism ethics during the management and operation of their tourism businesses. However, tourism's relationship with the environment is complex (Setokoe, 2013). It involves many activities that may have adverse environmental effects. Many of these impacts are linked to the construction of general infrastructures such as roads, airports, and of tourism facilities, including resorts, hotels, restaurants, shops, golf courses and harbours. Some studies suggest that on a negative note, tourism causes traffic and pedestrian congestion, parking problems, disturbance and destruction of flora and fauna, air and water pollution, and littering (Dwyer et al., 2020). In a study done by Costa et al. (2020) on the impacts of tourism and residents' perception, the results of this research revealed that residents have a positive attitude concerning economic, as well as cultural, social and environmental impacts. The study also reveals differences in attitude depending on age, gender and professional activity. The large increase of tourism activities that affects the environment in the Eastern Cape, particularly in Butterworth, raises concern about its negative environmental impacts (The Eastern Cape Socio-Economic Consultative Council, 2020). The negative impacts of tourism development may gradually destroy the environmental resources on which it depends. Butterworth (Xhosa: Gcuwa) is the case study area and it is a town in Mnquma Local Municipality in the Eastern Cape province of South Africa. Butterworth, is one of the oldest towns in the Eastern Cape's Wild Coast (the former Transkei - a black homeland during the apartheid years).

It was established originally as a Wesleyan mission station in 1827 (Mnquma Local Municipality, 2020). Tourism may cause friction and have a negative environmental impact, with seasonality being one of the most relevant negative consequences. During the high tourism season, public and leisure infrastructures become saturated and traffic congestion and parking problems occur (Oladeji et al., 2016). Therefore, the importance of researching the environmental impacts of tourism cannot be overestimated. Tichaawa and Mhlanga (2015) assert that, once a community becomes a tourist destination, the lives of the residents in that community are affected by the tourism activities.

\footnotetext{
${ }^{*}$ Corresponding author
} 
The effects involved may include overcrowding, increased crime, an increased cost of living, friction between tourists and residents, and changes in the host way of life (Caldicott et al., 2020). According to Arintoko et al. (2020) the lack of consideration of the environmental impacts could pose as a threat to the sustainability of the tourism in the Bawa community. Chang et al., (2018) note that rural communities, such as the Bawa of Butterworth, are a cause for great concern because of the increase in the negative environmental impacts of tourism. If these challenges are not well managed, they may cause a problem which becomes a major issue in the protection of the environment. Therefore, the purpose of this study was to determine the residents'perceptions of the environmental impacts of tourism in the Bawa community of Butterworth, South Africa and fill the gap in literature with regard to the environmental impact of tourism.

\section{Research objectives}

The main objectives to writing this paper are:

- To determine the perception of local residents of the negative environmental impact of tourism in the Bawa community of Butterworth, South Africa.

- To examine the factors that contributes to the environmental impact of tourism in the Bawa community of Butterworth, South Africa.

- To add to the body of knowledge pertaining tourism and the environment.

\section{LITERATURE REVIEW}

Butterworth, is one of the oldest towns in the Amatole region of the Eastern Cape Province in South Africa. Butterworth provides visitors with an opportunity to enjoy a real taste of South African mingled with traditional Xhosa hospitality. Butterworth is surrounded by beautiful country side with wide landscapes and vistas. With nearby villages one may take a day's walk to experience a welcoming customary Xhosa living (Mnquma Local Municipality, 2020). According to the Stainton (2020), the tourism industry depends on the natural environment for its existence, such as the Bawa community in the Eastern Cape Province. The town is rich in natural tourism resources, such as the Bawa Falls: The Bawa Falls is situated in the Bawa community and of all the natural waterfalls in the area, the $103 \mathrm{~m}$ Bawa Falls is one of the most impressive and receives a high volume of tourists in the area (Mnquma Local Municipality, 2020). Tourism and the environment depend on each other in order maintain natural resources (Setokoe, 2013). Many countries recognise this active industry as a key source of income, employment and private sector growth. Tourism is one of the industries that help countries to achieve their economic, environmental and social aims (Faladeobalade and Dubey, 2014). Many forms of tourism, especially those dependent on visiting particular places, heavily rely on natural resources and the culture of the region. As a result, an explanation of the environment and cultural heritage is one of the main topics of tourism development in the present age. According to Stainton (2020) in tourism, there is a mutual relationship between the physical environment and socio-cultural environment (the physical environment includes earth, air, water, vegetation, wildlife and man-made structures).

\section{TOURISM AND THE ENVIRONMENT}

Tang (2015) claims that understanding the relationship between tourism and the environment is important because of the complex interaction of the environmental impact arising from tourism. According to Rizal et al. (2020) environmental impacts are necessary to watch over and considered as the foundation of decision-making for the readiness of any tourism development. Rasekhi et al. (2016) argues that a related reliance exists between the development of tourism and the quality of the environment. In other words, the tourism industry and all other economic endeavours impact the environment directly, leading to the investment of those attracted to tourism in the value of the environment and the sustainable use of local resources. On the other hand, tourism is so dependent on the natural environment that the quality of the environment in the target area is one the major considerations when looking at the demands of tourism (Campbell, 2013). In addition, tourism depends on natural resources such as water, coastlines, landscapes and biodiversity, all of which affect the potential attractions of tourist destinations. According to Yazdanpanah (2016) environmental degradation created by tourism development, along with a lack of dedicated and organised management of the preservation of natural resources, brings about economic decline in many tourist destinations. The achievement of a good and desirable relationship between tourism and the environment, or between the potentially conflicting expectations and targets of visitors and local communities, could create many openings and opportunities (Kim et al., 2013). According to Sompholkrang (2014), tourism affects, and is affected by, the environment both directly and indirectly. However, the environment is considered for as an attraction for and a product of tourism. If the destination is crowded because of increased numbers of domestic and international tourists, the environment may be at risk and tourists might choose other travel destinations. Therefore, tourism might play a vital role in the safeguarding of natural habitats and nature against numerous critical forms of development (e.g., mining) or prevent other damaging forms of human activities (e.g., illegal hunting) through the earnings made by tourists 'visits (Sompholkrang, 2014).

\section{ENVIRONMENTAL IMPACTS OF TOURISM}

Negative impacts from tourism occur when the level of visitor use is greater than the environment's ability to cope with this use. Uncontrolled conventional tourism poses potential threats to many natural areas around the world (Stainton, 2020). It is clear that the growth in tourism contributes to major environmental damage and enforces critical social and cultural impacts on many destinations.

\section{Air and water pollution}

According to Bradford (2018) pollution is the contamination of a substrate when harmful and foreign substances are added to it. The additive substances can be of any form: solid, liquid or gas. This leads to the poisoning of the medium, making it unfit to be used. Wateris an important environmental element for tourist host destinations and is considered an important and scarce resource. Arulappan (2016) maintains that the tourism sector is acknowledged for its mistreatment and overconsumption of water resources. In shop owners, restaurants, hotels and the resident population polluting the water. The tourism industry is one of the vital contributors to greenhouse gas (GHG) emissions and is identified as contributing about $5 \%$ of carbon dioxide $\left(\mathrm{CO}^{2}\right)$ emissions globally (Bradford, 2018), of which $40 \%$ is a result of air travel. Therefore, the transportation sector of tourism is measured to be a main contributor of energy consumption (resulting in carbon emissions) and uses 243 million tons of fuel (6.3\% of the global production of fuel) annually (Arulappan, 2016). Sordello et al. (2019), believe that air pollution is created by both land and air transportation as a result of the rapid volume of tourists and their movements.

\section{Noise pollution}

Even though humans cannot see or smell noise pollution, it still affects the environment. Noise pollution happens when the sound coming from planes, industry or other sources reaches harmful levels. Underwater noise pollution coming from ships has been shown to upset whales' navigation systems and kill other species that depend on the natural underwater world (Bradford, 2018). Noise pollution could perhaps become a worldwide matter of concern, affecting the conservation of natural environments due to environmental disruption, ecosystems'destruction and loss of biodiversity (Sordello et al., 2019). Additionally, it is suggested that human-induced noise pollution is increasing into a worldwide destroyer of natural surroundings. 


\section{Solid waste and littering}

Bawa recieves a number of tourists due to its attractive scenery with its almost ever-green thorn trees and tropical flowers. Bawa Falls has a popular picnic spot and more adventurous hikers can camp overnight (Mnquma Local Municipality, 2020). In areas with concentrates of tourist activities and natural attractions, such as the Bawa area, waste disposal is a serious problem and im proper disposal can be a major despoiler of the natural environment. Tourist generates a great deal of waste at river sites, scenic areas and roadsides and in mountain and hiking areas (Stainton, 2020). Moreover, tourists on tour leave behind their waste, oxygen cylinders and even camping equipment. Such practices degrade the environment, particularly in remote areas because they have few litter collection or disposal facilities (Bradford, 2018). Improper management of solid waste is one of the main causes of environmental pollution and land pollution which is one of the 17 major forms of environmental disaster our world is facing today (Abdel-Shafy and Mansour, 2018). Many tourists are found littering the natural environment while engaging in tourist activities such as hiking or other nature-based activities. This is not only degrading to the environment by also results in visual pollution (Yang et al., 2015).

\section{Overcrowding and congestion}

Butterworth is home to the first and only shopping centre in the area, which could lead to the overcrowding. The overcrowding of tourists in specific areas causes much harm to the local community in terms of traffic congestion and issues of parking space which result in conflict between locals and tourists (Szromek et al., 2018). However, the growth of tourism has also brought with it much employment and economic opportunities but tourist destinations become overpopulated with people and this has a negative effect on the environment. The attractiveness of natural resources may therefore, result in the misuse of resources by the population. Zhong et al., (2011) maintains that these environmental issues related to tourism not only impact on the image of the tourist destinations but also on the sustainable development of the local tourism industry.

\section{METHODOLOGY}

The reseach study made use of both quantitative and qualitative methods. Primary data for the current study was gathered using a questionnaire survey. A total number of 158 questionnaires were successfully collected among the residents of Bawa community in Butterworth, South Africa. The questionnaire consisted of 12 closed-ended questions and 3 open-ended questions. The closed-ended questions were designed to find out whether the respondents have an understanding of tourism and the environment and to further determine their perception of the impacts of tourism within Bawa community. A qualitative method was selected in a form of open-ended questions. In this case, the aim of the researcher was for the respondents to further express their opinions and views in relation to the environmental impacts of tourism in Bawa community. The study adopted a simple random method to identify a suitable sample from Bawa local community in Butterworth because it is very easy to assess the sampling errors in the method. Etikan and Bala (2017) describe simple random sampling as a sampling which permits every single item from the universe to have an equal chance of presence in the sample. For the study, the statistical package for the Social Sciences (SPSS) software was used to capture the results of the data that was collected.

\section{RESULTS}

Tourism being a travel industry, it is important to understand the environmental impacts that are caused by tourism in a community. Therefore, this study pursued to determine the demographic profile of the community of Bawa in Butterworth.Table 1 shows that the highest percentage who participated in the present study are female (59\%) compared with $41 \%$ of male respondents. The ethnic group of the respondents found to be black people $(100 \%)$. With regards to educational levels the majority of the respondents successfully completed secondary school at $34 \%$. These were followed by undergraduate students, at $17 \%$. A total of $16 \%$ of the respondents had postgraduate qualifications and $15 \%$ of the respondents had obtained a certificate. An overwhelming $32 \%$ of the respondents did not reveal their income.

Table 1. Demographic profile of the respondents

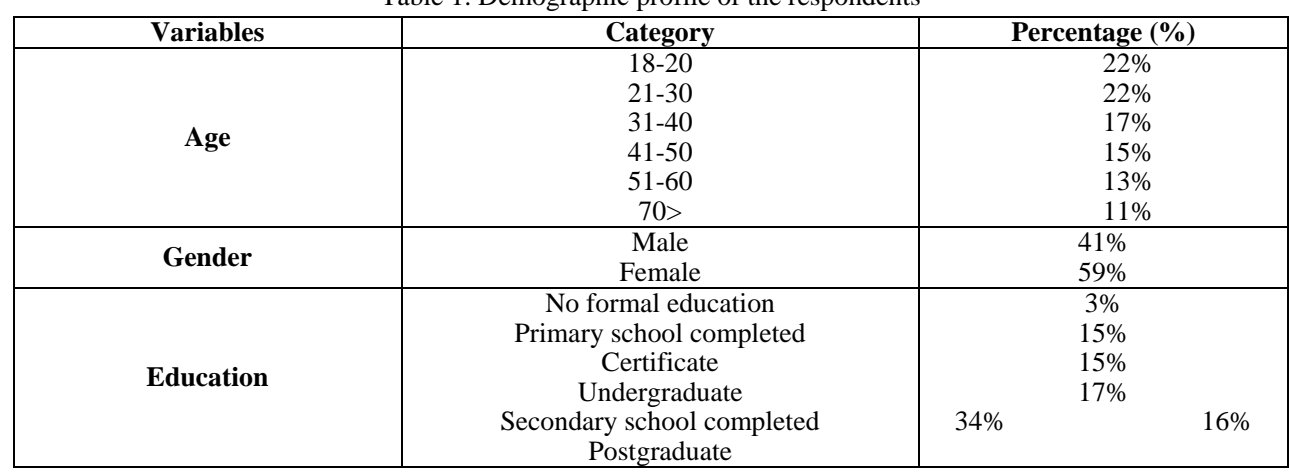

Table 2. Resident's perception of environmental impacts created by tourism

\begin{tabular}{|c|c|c|c|c|c|}
\hline \multirow[t]{2}{*}{ Statements } & \multicolumn{5}{|c|}{ Percentage obtained } \\
\hline & $\mathbf{S A}$ & $\mathbf{A}$ & $\mathbf{N}$ & $\mathbf{D}$ & SD \\
\hline Tourists are likely to drop litter & 56 & 26 & 6 & 10 & 2 \\
\hline Tourism can contribute to congestion in terms of overcrowding of people as well as traffic congestion & 44 & 45 & 8 & 3 & - \\
\hline Tourism may lead to damage and/ or disturbance of wildlife habitats & 16 & 51 & 20 & 12 & 1 \\
\hline Tourism can contribute to the pollution (air, water and noise) & 46 & 36 & 8 & 7 & 3 \\
\hline
\end{tabular}

1= Strongly Agree (SA): 2= Agree (A): 3= Neutral (N): 4= Disagree (D): 5= Strongly Disagree (SD)

The respondents were asked to indicate their understanding of tourism and the environment. Most (28\%) of the respondents indicated that tourism and the environment depend on each other in order to maintain the natural resources. A total of $27 \%$ stated that the tourism industry depends on the natural environment for its existence, while $26 \%$ of the respondents indicated that tourism activities take place within the environment. Some respondents (16\%) thought that the quality of the environment is essential to tourism. The participants were provided with statements linked to some tourism environmental impacts and were asked to rate their perception on each. The findings of the study in table 2 reveal that the majority of respondents (56\%) strongly agreeing and $26 \%$ agreeing, that respondent thinks that tourists are likely to drop litter. While (45\%) of the respondents agree and $44 \%$ strongly agree that tourism contributes to overcrowding and traffic congestion. Furthermore, the majority of the respondents ( $46 \%$ strongly agree \& $36 \%$ agree) perceive that tourism contributes to pollution. Most of the respondents (39\%) indicated that they agreed that there is no environmental monitoring whereas $9 \%$ strongly agreed. A total of $31 \%$ were neutral, while $16 \%$ of the 
respondents disagreed with the statement. The findings show that the majority of the respondents agree with the statement that the government does not promote environmental awareness effectively, with $39 \%$ and $13 \%$ who noted that they strongly agree. The findings therefore indicate that the respondents feel that the government needs to promote environmental awareness programmes in the Bawa communities, in Butterworth.

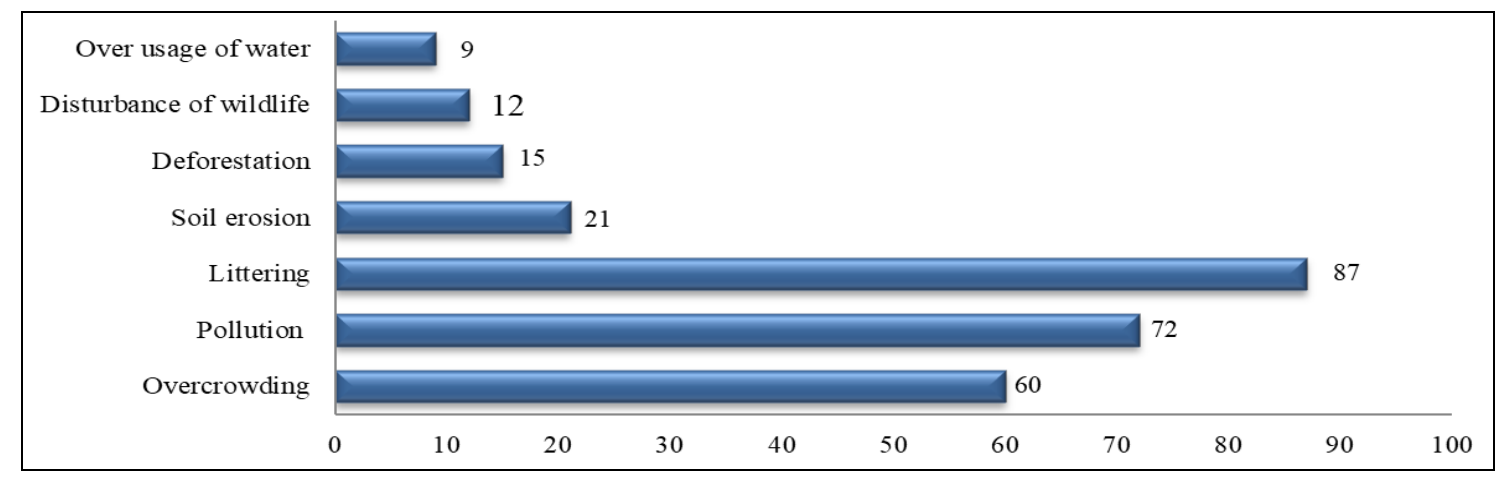

Figure 1. The environmental impacts of tourism on the Bawa community

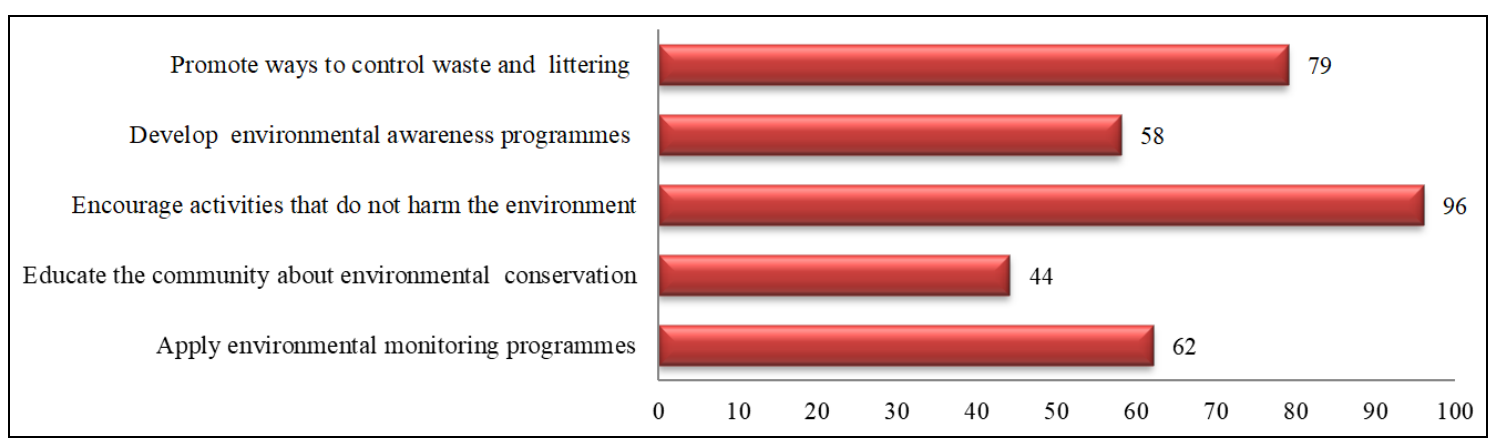

Figure 2. Effective measures to maintain the environment

The respondents were asked to indicate any tourism related challenges that affect the community environmentally. Figure 2 presents the negative impacts that were indicated by the respondents. The highest percentage of the respondents (87\%) stated littering as a major environmental impact, and in agrrement a study by Solberg (2017) has concluded that litter is an environmental impact which has been proven to be the most easily seen and perceived by the local community. Further $72 \%$ of the respondents stated pollution. Inversely, the study initiate that local community were of the view that they should apply effective measures to safeguard the environment.

The study wanted to find out from the residents of Bawa what they think could be done to overcome the challenges highlighted in Figure 1 . The findings in Figure 2 above show that the majority of the respondents $(96 \%)$ indicated that effective measures to safeguard the environment should be introduced, whereas 58\% mentioned that environmental awareness programmes were required. A total of $62 \%$ of the respondents suggested that environmental monitoring during high tourism season should take place. Furthermore, $79 \%$ of the respondents stated that control of waste and littering was needed, while $44 \%$ indicated that education about how to conserve the environment was essential. Through education one can increase the community awareness and knowledge about present environmental issues or problems. This will equip the public with the necessary skills to make informed decisions and take responsible action (Retief, 2018). Dolnicar et al. (2019) recognise that responsible tourism behaviour can minimise environmental challenges and can be considered a solution to the negative environmental impacts.

\section{RESEARCH RECOMMENDATIONS}

Tourism has the potential to create beneficial effects on the environment by contributing to environmental protection and conservation. It is a way to raise awareness of environmental values and it can serve as a tool to finance protection of natural areas and increase their economic importance (Stainton, 2020). The key aim of the research was to determine residents 'perceptions of the environmental impacts of tourism on the Bawa community in Butterworth. The paper provises a sound basis for tourism businesses and the government to actively engage in activities to protect and preserve the environment. The local community perceived the greatest environment impact to be increased waste disposal, littering and overcrowding. It is therefore recommended that waste disposal should be appropriately addressed by constant monitoring and assessments that adhere to accepted environmental standards. A lack of government support was also noted by the local community. Therefore, it is recommended that tourism stakeholders should acknowledge the importance of the local community.

It is suggested that tourism planners in Butterworth apply effective measures to safeguard the environment and to increase environmental awareness campaigns to educate the local community about the importance of protecting the natural resources for the current and future generations. Bob (2016) asserts that information distribution through practices such as awareness campaigns may encourage tourists and the local community to be more environmentally responsible when travelling. Government also needs to play a role in creating added public environmental awareness campaigns regarding sustainable issues to reduce their negative impacts. Employment opportunities should be offered to the community to distribute the benefits and to reduce the challenges imposed on the local people. To avoid these negative issues, it is recommended that tourism planners should encourage the local community to be more involved in decision-making and in tourism planning and that they should include sustainable measures and practices to help protect the environment.

\section{CONCLUSION}

The study contributed to an improved understanding of the environmental impacts created by an increase of tourism. Determining how to minimise the negative tourism impacts is important since such impacts may have implications for the future growth and development of the tourism sector. The current study could play essential role in assisting stakeholders and tourism authorities in the Eastern Cape, particularly in Butterworth, in tourism development planning. 
The study aimed to determine how the local community perceives the environmental impacts of tourism. It provides insight into the perceptions of the local community regarding the negative environmental impacts of tourism on Butterworth. The study further aims to encourage the local communities of Butterworth to be more involved in tourism development. Furthermore, the study makes a contribution to a largely under-researched area concerning environmental impacts of tourism, specifically in the Eastern Cape Province.

\section{REFERENCES}

Abdel-Shafy, H., \& Mansour, H. (2018). Solid waste issue: Sources, composition, disposal, recycling, and valorization. Egyptian Journal of Petroleum, 27(4), 1275-1290. https://doi.org/10.1016/j.ejpe.2018.07.003

Arintoko, A., Ahmad, A.A., Gunawan, D.S., \& Supadi, S. (2020). Community based tourism village development strategies: a case of Borobudur tourism village area, Indonesia. GeoJournal of Tourism and Geosites, 29(2), 398-413. https://doi.org/10.30892/gtg.29202-477

Arulappan, L. (2016). Environmental impacts of ecolabels on the tourism sector of South Africa.Masters Dossertation, Durban University of Technology. Durban, Kwazulu Natal.

Bob, U. (2016). An assessment of responsible tourism behaviour among beach tourists in Durban, South Africa. African Journal of Hospitality, Tourism and Leisure, 5(3), 1-15. https://doi.org/10.46222/ajht1.19770720-5

Bradford, A. (2018). Pollution Facts \& Types of Pollution. Future US Inc, New York, United States.

Caldicott, R.W., von der Heidt, T., Scherrer, P., Muschter, S., \& Canosa, A. (2020). Airbnb - exploring triple bottom line impacts on community. International Journal of Culture, Tourism and Hospitality Research, 14(2), 205-223. https://doi.org/10.1108/IJCTHR-07-2019-0134

Campbell, S.J. (2013). Co-management approaches and incentives improve management effectiveness in the Karimunjawa National Park, Indonesia. Marine Policy, 41(22), 72-79. https://doi.org/10.1016/j.marpol.2012.12.022

Chang, K., Hungju Chien, H., Cheng, H., \& Chen, H. (2018). The Impacts of Tourism Development in Rural Indigenous Destinations: An Investigation of the Local Residents' Perception Using Choice Modeling. Susainability, 10(4766), 1-15. https://doi.org/10.3390/su10124766

Costa, A., Umbelino, J., Calisto, M., Nunes, S., \& Afonso, V. (2020). Impacts of Tourism and Residents' Perceptions: A Study in the Regional Tourism Area of Lisbon. European Journal of Tourism, Hospitality and Recreation, 10(1), 28-40. https://doi.org/10.2478/ejthr-2020-0003

Cucculelli, M., \& Goffi, G. (2015). Does sustainability enhance tourism destination competitiveness?. Evidence from Italian Destinations of Excellence. Journal of Cleaner Production, 1(13), 1-10. https://doi.org/10.1108/CR-12-2017-0086

Dahal, B., K.C.A., \& Sapkota, R. (2020). Environmental Impacts of Community-Based Home stay Ecotourism in Nepal. The Gaze: Journal of Tourism and Hospitality, 11(1), 60-80. https://doi.org/10.3126/gaze.v11i1.26618

Diedrich, A., \& García-Buades, E. (2009). Local perceptions of tourism as indicators of destination decline. Tourism Management, 30(4), 512-521. https://doi.org/10.1016/j.tourman.2008.10.009

Dolnicar, S., Knezevic Cvelbar, L., \& Grün, B. (2019). A sharing-based approach to enticing tourists to behave more environmentally friendly. Journal of Travel Research, 58(2), 241-252. https://doi.org/10.1177/0047287517746013

Dwyer, L., Forsyth, P., \& Dwyer, W. (2020). Tourism Economics and Policy. Channel View Publications, Bristol, United Kingdon.

Etikan I, Bala K. Sampling and sampling methods. (2017). Biom Biostat International Journal, 5(6), 215-217. https://doi.org/10.15406/bbij.2017.05.00149

Faladeobalade, T., \& Dubey, S. (2014). Managing Tourism as a source of Revenue and Foreign direct investment inflow in a developing Country: The Jordanian Experience. International Journal of Academic Research in Economics and Management Sciences, 3(3), 1-15. https://doi.org/10.6007/IJAREMS/v3-i3/901

Kim, K., Uysal, M., \& Sirgy, M.J. (2013). How does tourism in a community impact the quality of life of community residents? Tourism Management, 36(9), 527-540. https://doi.org/10.1016/j.tourman.2012.09.005

Lee, T., Jan, F., \& Yang, C. (2013). Conceptualizing and measuring environmentally responsible behaviors from the perspective of community-based tourists. Tourism Management, 36(3), 454-468. https://doi.org/10.1016/j.tourman.2012.09.012

Lundberg, Erik. (2015). The Level of Tourism Development and Resident Attitudes: A Comparative Case Study of Coastal Destinations. Scandinavian Journal of Hospitality and Tourism, 15(2), 1-29. https://doi.org/10.1080/15022250.2015.1005335

Mangwane, J., Tshipala N.N., Ntanjana, A., \& Makopo, B.M. (2019). Segmenting township residents by their attitudes, behaviours, and opinions towards responsible tourism practices. GeoJournal of Tourism and Geosites, 27(4), 1357-1366. https://doi.org/10.30892/gtg.27420-439

Manzoor. F., Wei, L., Asif, M., Haq, M., \& Rehman, H. (2019). The Contribution of Sustainable Tourism to Economic Growth and Employment in Pakistan. International Journal of Environmental Res Public Health, 16(19), 25-37. https://doi.org/10.3390/ijerph16193785

Nash, J. (2020). Eco-Tourism: Encouraging Conservation or Adding to Exploitation?. Population Reference Bureau, Washington, United States.

Oladeji, K.I., Mbaiwa, J.E., \& Mmopelwa, G. (2016). The environmental impacts of tourism on community people‘s quality of life in Maun, Botswana. African Journal of Hospitality, Tourism and Leisure, 5(4), 1-11. https://doi.org/72f99b83501a315b894a34513

Rasekhi, S., Karimi, S., \& Mohammadi, S. (2016). Environmental impacts of tourism, A case study of selected developing and developed countries. The Journal of Tourism Planning and Development, 5(16), 71-94. https://doi.org/10.1007/s11356-019-07372-4

Retief, L. (2018). The Importance of Environmental Education. Natures Valley Trust, The Crags, Plettenberg Bay.

Rizal, A., Apriliani, I.M., \& Permana, R. (2020). Sustainability assessment of coastal development in Southern region of West Java province, Indonesia. GeoJournal of Tourism and Geosites, 30(2), 808-817. https://doi.org/10.30892/gtg.302sp105-509

Robinot, E., \& Giannelloni, J.L. (2010). Do hotels' green attributes contribute to customer satisfaction? Journal of Services Marketing, 24(2), 157-169. https://doi.org/10.1108/08876041011031127

Setokoe, T.J. (2013). Tourism Development 1. Walter Sisulu University, East London, Eastern Cape.

Solberg, A. (2017). Tourist perceptions of their environmental impacts in Tanzania. Masters Dissertation, Kent State University. Kent, Ohio.

Sompholkrang, M. (2014). Tourism expenditures and environment in Thailand.Eurasian Journal of Economics and Finance, 2(2), 63-69. https://doi.org/10.15604/ejef.2014.02.02.005

Sordello, R., Flamerie De Lachapelle, F., \& Livoreil, B. (2019). Evidence of the environmental impact of noise pollution on biodiversity: a systematic map protocol. Environmental Evi, 8(8), 332-345. https://doi.org/10.1186/s13750-019-0146-6

Stainton, H. (2020). TEFL Tourism: Principles, Commodification and Sustainability. CABI Publishing, Wallingford, United Kindgdom.

Szromek, A., Hysa, B., \& Karasek, A. (2018). The Perception of Overtourism from the Perspective of Different Generations. Sustainability, 11(15), 1-19. https://doi.org/10.3390/su11247151

Tang, Z. (2015). An integrated approach to evaluating the coupling coordination between tourism and the environment.Tourism Management, 46(3), 11-19. https://doi.org/10.1016/j.tourman.2014.06.001

Tichaawa, T., \& Mhlanga. (2015). Community perceptions of a community-based tourism project: A case study of the CAMPFIRE programme in Zimbabwe. African Journal for Physical, Health Education, Recreation and Dance, 21(1), 55-67. http://dx.doi.org/10.1515/19595

Tony, B. (2019). The Greening of Machiavelli: The Evolution of International Environmental. Routledge, Abingdon, Kwazulu Natal.

Vargas-Sánchez, A., Plaza-Mejia, M., \& Porras-Bueno, N. (2009). Understanding residents' attitudes toward the development of industrial tourism in a former mining community. Journal of Travel Research. 47(3), 373-387. https://doi.org/10.1177/0047287508322783

Yang, J., Han, Q., Zhou, J., \& Yuan, C. (2015). The Influence of Environmental Management Practices and Supply Chain Integration on Technological Innovation Performance-Evidence from China's manufacturing Industry. ESP Ind, Beijing, China.

Yazdanpanah, H. (2016). Effect of climate change impact on tourism: A study on climate comfort of Zayandehroud River route from 2014 to 2039 . Tourism Management Perspectives, 17(3), 82-89. https://doi.org/10.1016/j.tmp.2015.12.002

Zhong, L., Deng, J., Song, Z., \& Ding, P. (2011). Research on environmental impacts of tourism in China: Progress and prospect. Journal of Environmental Management, 92(11), 2972-2983. https://doi.org/10.1016/j.jenvman.2011.07.01

*** Mnquma Local Municipality. (2020). Welcome message. Mnquma Local Municipality, Butterworth, Eastern Cape.

*** The Eastern Cape Socio-Economic Consultative Council, (2020). A Socio Economic Profile of Butterworth. Ecsecc, Butterworth, Eastern Cape. 